\title{
Suppression of sourness: A comparative study involving mixtures of organic acids and sugars
}

\author{
LOTIKA SAVANT and MINA R. MCDANIEL \\ Oregon State University, Corvallis, Oregon
}

\begin{abstract}
The degree of sourness suppression of perceptually equisour levels of citric, lactic, and malic acids by equal molar and weight amounts of sucrose, fructose, and glucose was determined in binary mixtures. Equisour acid levels were obtained by magnitude estimation. Mixture intensity ratings were collected on a categorical scale, using trained panelists. In general, equal sugar molarities and weights did not effect equivalent suppression. Instead, the perceived intensity of the sugars appeared to suppress sourness more systematically, implying that dominantly central neural mechanisms underlie suppression. This was confirmed when no significant differences were found between the suppressive abilities of sweetnessmatched levels of sucrose, fructose, and an equiratio mixture of the two on citric acid sourness. The possibility of a separate receptor site/mechanism for glucose and a small peripheral component to suppression is also suggested.
\end{abstract}

Acids have many functions in food systems, including preserving, buffering, flavoring, and chelating. Acids are routinely used in the food industry as a means of lowering the $\mathrm{pH}$ of foods and beverages to enhance their shelf lives. Acidification of heat-sensitive, low-acid foods allows for commercial sterility with milder heat treatment (Sognefest, Hays, Wheaton, \& Benjamin, 1948), thereby providing lower energy usage and overall cost reduction. However, the addition of commonly used food-grade organic acids alters the flavor of acidified foods, often rendering them unpalatable. As a result, only a few low-acid foods with the ability to tolerate such acid flavors have been successful candidates for acidification (McCarthy, Heil, Krugermann, \& Desvignes, 1991).

Suppression or partial masking of sourness regularly occurs in complex food systems. It is well known that sweeteners constitute one of the most effective masking agents for sourness. Sweeteners are combined in the formulations of acidified foods to achieve optimum taste, while maintaining the desired $\mathrm{pH}$. However, the most effective sweet masker(s) for a particular acid and the optimal level or range of the masker, given the acid concentration, are usually ascertained by a trial-and-error approach.

Mixture interactions have been variously examined in the literature, but the interaction of tastants with a view to

The authors thank Harry Lawless for his helpful suggestions on an early draft of this article and Cindy Lederer for technical editing. Correspondence concerning this article should be addressed to M. R. McDaniel, Department of Food Science and Technology, Oregon State University, 100 Wiegand Hall, Corvallis, OR 97331-6602 (e-mail: mina.mcdaniel@) orst.edu).

Note-This article was accepted by the previous editorial team, headed by Neil Macmillan. achieving suppression of sourness has not received much attention. In studies involving interactions between sweet and sour tastants, citric acid and sucrose have primarily been used. Suprathreshold levels of citric acid have been shown to suppress sucrose sweetness (Pangborn, 1961). Sucrose was reported to suppress the perceived intensity of citric acid (McBride, 1989; McBride \& Johnson, 1987). Schifferstein and Frijters (1991) reported that equisweet levels of aspartame, saccharin, fructose, and sucrose were equally effective in suppressing the perceived sourness of citric acid, whereas McBride and Finlay (1990) found that sucrose suppressed the sourness intensity of citric acid more effectively than did fructose. Mutually suppressing interactions between citric acid and the sweeteners aspartame and sucrose revealed that there was a greater suppression of sweetness by acid levels than of sourness by increasing sweetener levels (Bonnans \& Noble, 1993).

The phenomenon of taste suppression, in general, depends on three main factors: (1) the type of suppressing taste substance, (2) the physical intensity of the suppressing component, and (3) the relative number of components that make up the mixtures (Kroeze, 1989). With respect to the physical intensity of the suppressing component, it has not been clearly established whether the weight, the molarity, or the perceived intensity of the suppressor is a significant determinant of the resulting suppression. Our goal in this study was to better understand the role played by each of these factors. A relationship between sourness suppression and sugar molarity would favor molecular mechanisms as being responsible for the suppression, whereas one with sugar weight might implicate physical effects, such as viscosity. On the other hand, a correspondence with perceived sugar sweetness would be indicative of neural effects (central/peripheral). Although the idea that suppression in sweet-sour mixtures is a perceptual phenomenon related 
to the perceived intensity of the masking agent has been explored (Schifferstein \& Frijters, 1991), the work was limited to sourness suppression of citric acid alone, and the effects of the molarity or the weight of the masker were not concurrently examined.

Our objective was to determine the effects of the molarity, weight, and perceived sweetness intensity of three sugars on the perceived sourness intensity of three food-grade organic acids at perceptually equisour levels in a waterbased model system. The results were confirmed by testing the effects of equisweet concentrations of two of the sugars on the sourness of one acid.

\section{METHOD}

\section{Subjects}

The subjects were selected on the basis of performance in a prescreening exercise that tested for sensitivity and reproducibility via a ranking test. Seventeen panelists (12 women and 5 men) qualified for participation. The subjects' ages ranged from 19 to 30 years. The subjects included staff and students at Oregon State University and residents from the local community. All were compensated for their participation.

\section{Stimuli}

Food-grade solutes were $>99 \%$ pure, with the exception of lactic acid (calcium salt form), which was $\sim 60 \%$ pure. The solutions were made in distilled water. Citric, lactic, and malic acids were used in the mixtures, and acid levels were selected by a sourness-matching exercise to be equisour with 0.00625 and $0.025 \mathrm{~mol}$ citric acid, designated low and high, respectively. The equisour acid levels were determined through trained panel evaluation using magnitude estimation (Stevens, 1956, 1957). The testing protocol followed Rubico (1993) and Moskowitz and Sidel (1971), wherein trained panelists evaluated sourness, using a reference modulus $(0.00625 \mathrm{~mol}$ citric acid). Sourness-matched levels were determined from the power functions of the acids generated through magnitude estimation (Figure 1).

The sweeteners used were sucrose, fructose, and glucose. Sweetener levels were designated low and high, corresponding to 0.0625 and $0.25 \mathrm{~mol}$ on a molar basis and 11.25 and $45 \mathrm{~g} / \mathrm{L}$ on a weight basis. The molar values were selected on the basis of literature values and pilot testing. The listed weight levels were selected because the sugars glucose and fructose fortuitously have identical formula weights and molecular weights, thereby allowing a reduction in the total number of samples to be tested. Sucrose has a different formula weight and molecular weight; therefore, for the purposes of experimental design and analysis, it was treated as two sweeteners (i.e., sucrose equimolar and sucrose equiweight). A sugar-free acid control was simultaneously tested at every level of each acid. All the stimulus concentrations are presented in Table 1 . This resulted in a factorial plus control experimental design [ 3 acids $\times 2$ acid levels $\times$ 4 sweeteners $\times 2$ sweetener levels) + acid control]. In addition, evaluation of all $48+$ control treatment combinations was conducted in duplicate, providing two replications.

The results from the work above were confirmed using two sugars (sucrose and fructose) and one acid (citric). Sweetness matching was performed on sucrose, fructose, and a 1:1 equiratio mixture of the two. Equiratio sugar mixtures were prepared on the basis of a procedure described by Frijters and Oude Ophuis (1983). Three sweetness-matched levels obtained from the sugar power functions (Figure 2) were used to test the effect of equisweet sugar concentrations on the suppression of citric acid sourness. The sugar levels selected from the plots were equisweet with $0.0313,0.0625$, and $0.125 \mathrm{~mol}$ sucrose. The concentration of citric acid in all the mixtures was fixed at $0.00625 \mathrm{~mol}$.

\section{Procedure}

The solutions were prepared $12-14 \mathrm{~h}$ before testing and were stored overnight at $4^{\circ} \mathrm{C}$. Prior to serving, solutions were allowed to equilibrate to room temperature $\left(21^{\circ}\right.$ to $\left.22^{\circ} \mathrm{C}\right)$. Approximately $30 \mathrm{ml}$ of each sample was presented in $85-\mathrm{ml}$ plastic cups, and the cups were coded with three-digit random numbers. Up to five samples were served in a set, and no more than four sets were presented each day. The serving order of samples was randomized within an acid type and level, with each sample being evaluated twice. The stimuli were sampled by the sip-and-spit method. This part of the study used category scaling, where subjects rate the intensities of stimuli by assigning them values on a limited, typically numerical scale (Meilgaard, Civille, \& Carr, 1991). Direct scaling of this type has its basis in the scaling developed by Thurstone, whose law of comparative judgment pointed out that the degree to which the psychological impressions of any two stimuli in a set overlap (i.e., the amount of con-

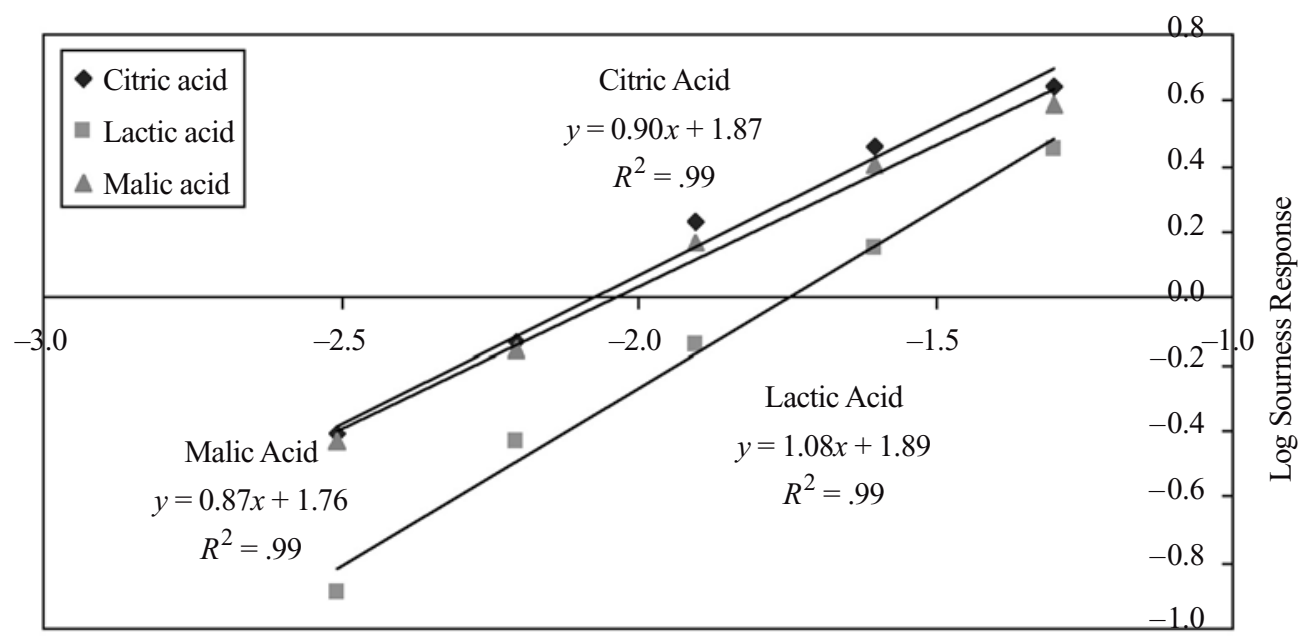

Log Molar Concentration

Figure 1. Power functions of acid sourness. Each data point represents the mean of 51 values (17 panelists $\times 3$ replications). 
Table 1

Stimulus Concentrations

\begin{tabular}{llllll}
\hline \multicolumn{1}{c}{ Sugar } & $\begin{array}{c}\text { Molarity } \\
\text { (in mol) }\end{array}$ & $\begin{array}{c}\text { Weight } \\
\text { (in grams/liter) }\end{array}$ & Acid & $\begin{array}{c}\text { Molarity } \\
\text { (in mol) }\end{array}$ & $\begin{array}{c}\text { Weight } \\
\text { (in grams/liter) }\end{array}$ \\
\hline Low glucose (Em/Ew) & 0.0625 & 11.25 & low citric & 0.00625 & 1.2 \\
Low fructose (Em/Ew) & 0.0625 & 11.25 & low malic & 0.0068 & 0.9112 \\
Low sucrose (Em) & 0.0625 & 21.375 & low lactic & 0.0142 & 2.166102 \\
Low sucrose (Ew) & 0.03289 & 11.25 & high citric & 0.025 & 4.8 \\
High glucose (Em/Ew) & 0.25 & 45 & high malic & 0.0288 & 3.8592 \\
High fructose (Em/Ew) & 0.25 & 45 & high lactic & 0.06283 & 9.58408 \\
High sucrose (Em) & 0.25 & 85.5 & & & \\
High sucrose (Ew) & 0.13158 & 45 & & & \\
\hline
\end{tabular}

Note_Em, equimolar; Ew, equiweight.

fusion between the stimuli) is enough information for one to infer the psychological distances among the various stimuli (Riskey, 1988). Upon tasting the samples, the panelists rated the sweetness and sourness intensities of the mixture solutions on a 16-point intensity scale $(0=$ none, $3=$ mild, $7=$ mild to moderate, $11=$ moderate, and $15=$ moderate to high). The panelists were trained in the use of the scale with the help of references and training exercises conducted prior to testing. The sourness references made with citric acid were as follows: sour $3(0.00313 \mathrm{~mol})$, sour $7(0.00625 \mathrm{~mol})$, sour $11(0.0125 \mathrm{~mol})$, and sour $15(0.025 \mathrm{~mol})$. The sweetness references were made with fructose at the following levels: sweet 3 $(0.0625 \mathrm{~mol})$, sweet $7(0.125 \mathrm{~mol})$, sweet $11(0.25 \mathrm{~mol})$, and sweet $15(0.5 \mathrm{~mol})$. The panelists were encouraged to thoroughly rinse their mouths with water between samples. The subjects were also asked to refrain from smoking, eating, or drinking anything for at least a half hour before testing. The $\mathrm{pH}$ of all the controls and binary mixture solutions was recorded prior to testing.

\section{Data Analysis}

Sessions were separated by acid type (citric, malic, or lactic) and level (low or high), giving a total of six sessions. The data were analyzed using a mixed-model analysis of variance within session, with Tukey's honest significant difference as the post hoc means separation procedure. Analyses were conducted using SPSS Version 8.0 (1997). Model effects were treatment (sugar name and level; fixed effect), panelist (random effect), and the interaction of panelist and treatment (random effect).
For the confirmation, the analysis was conducted within a sweetness-matched sugar level obtained from the sugar sweetness functions in Figure 2.

\section{RESULTS}

\section{The Effect of Equiweight and Equimolar Sugar Concentrations and the Effect of Perceived Sweetness of the Sugars at Equiweight Levels}

Mean sourness and sweetness intensity ratings for all the mixtures are presented in Table 2. From this point on, sourness suppression, or the degree of suppression, will refer to a reduction in the sourness rating for a mixture solution, as compared with the sourness rating for the corresponding acid-only control.

Trends within acids and across sugars. From the values in Table 2, it can be seen that for the three acid mixtures at low and high acid levels, sourness suppression was significant for the mixtures with equimolar fructose, as well as equiweight sucrose, at the high sugar level ( $p<$ .05 ). In addition, mixtures of low- and high-level malic acid with equimolar sucrose at the low sugar level were found to show significantly more sourness suppression $(p<.05)$, as compared with the low sugar level mixtures

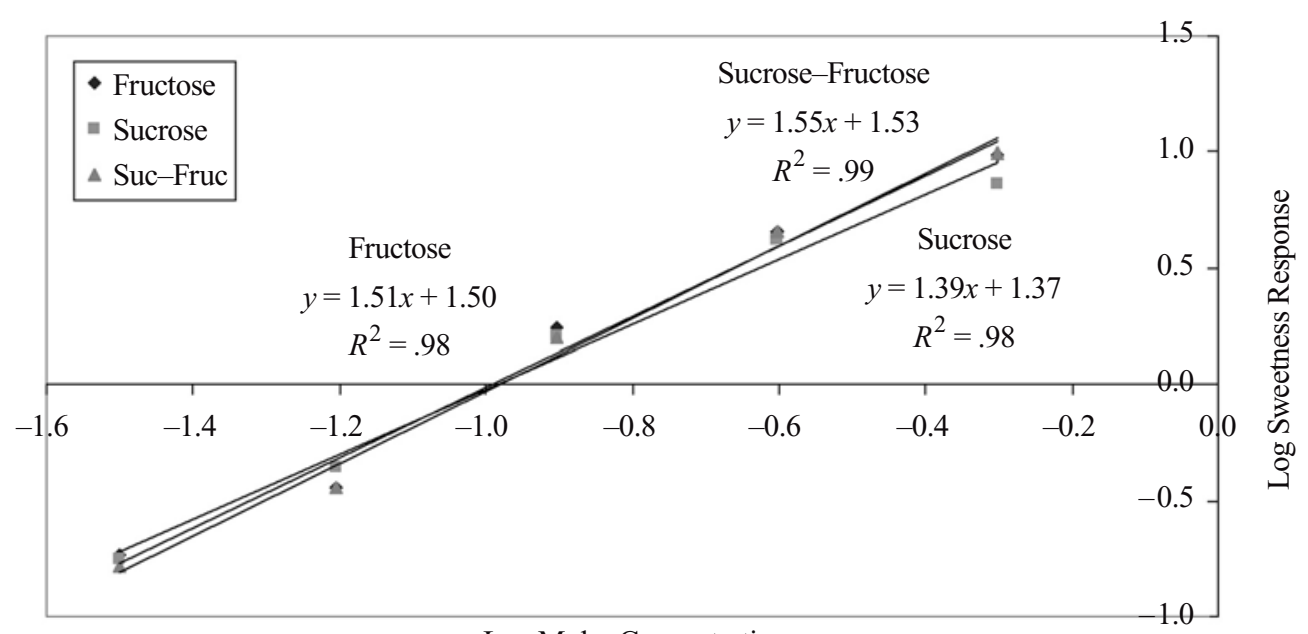

Log Molar Concentration

Figure 2. Power functions of sugar sweetness. Each data point represents the mean of 51 values (17 panelists $\times 3$ replications). 
Table 2

Mean Sourness and Sweetness Intensity Ratings for Control (No-Sugar) and Binary Acid-Sugar Mixtures at Low and High Sugar and Acid Levels

\begin{tabular}{|c|c|c|c|c|c|c|}
\hline \multirow[b]{2}{*}{ Sugar Level and Type } & \multicolumn{2}{|c|}{ Citric Acid Mixtures } & \multicolumn{2}{|c|}{ Lactic Acid Mixtures } & \multicolumn{2}{|c|}{ Malic Acid Mixtures } \\
\hline & Mean Sourness & Mean Sweetness & Mean Sourness & Mean Sweetness & Mean Sourness & Mean Sweetness \\
\hline \multicolumn{7}{|c|}{ Low Acid Level } \\
\hline $\begin{array}{l}\text { Control } \\
\text { Low fructose } \\
\text { Low glucose } \\
\text { Low sucrose (Em) } \\
\text { Low sucrose (Ew) } \\
\text { High fructose } \\
\text { High glucose } \\
\text { High sucrose (Em) } \\
\text { High sucrose (Ew) }\end{array}$ & $\begin{array}{l}8.53_{\mathrm{a}} \\
7.88_{\mathrm{a}} \\
8.35_{\mathrm{a}} \\
6.79_{\mathrm{ab}} \\
7.50_{\mathrm{a}} \\
5.53_{\mathrm{b}} \\
7.88_{\mathrm{a}} \\
5.06_{\mathrm{b}} \\
5.71_{\mathrm{b}}\end{array}$ & $\begin{array}{c}0.97_{\mathrm{f}} \\
3.38_{\mathrm{de}} \\
1.18_{\mathrm{f}} \\
4.85_{\mathrm{cd}} \\
2.18_{\mathrm{ef}} \\
10.32_{\mathrm{ab}} \\
5.18_{\mathrm{c}} \\
11.85_{\mathrm{a}} \\
9.12_{\mathrm{b}}\end{array}$ & $\begin{array}{l}7.97_{\mathrm{a}} \\
7.50_{\mathrm{a}} \\
8.32_{\mathrm{a}} \\
7.03_{\mathrm{ab}} \\
7.38_{\mathrm{ab}} \\
5.21_{\mathrm{cd}} \\
7.12_{\mathrm{ab}} \\
4.06_{\mathrm{d}} \\
6.09_{\mathrm{bc}}\end{array}$ & $\begin{array}{c}0.85_{\mathrm{f}} \\
3.00_{\mathrm{e}} \\
1.50_{\mathrm{f}} \\
4.32_{\mathrm{d}} \\
1.82_{\mathrm{f}} \\
9.26_{\mathrm{b}} \\
3.26_{\mathrm{de}} \\
11.88_{\mathrm{a}} \\
7.85_{\mathrm{c}}\end{array}$ & $\begin{array}{l}8.12_{\mathrm{ab}} \\
8.56_{\mathrm{a}} \\
8.50_{\mathrm{a}} \\
7.06_{\mathrm{bc}} \\
7.88_{\mathrm{ab}} \\
5.38_{\mathrm{d}} \\
8.06_{\mathrm{ab}} \\
3.74_{\mathrm{e}} \\
5.85_{\mathrm{cd}}\end{array}$ & $\begin{array}{c}0.97_{\mathrm{g}} \\
2.74_{\mathrm{e}} \\
1.21_{\mathrm{fg}} \\
4.59_{\mathrm{d}} \\
2.26_{\mathrm{ef}} \\
10.21_{\mathrm{b}} \\
3.97_{\mathrm{d}} \\
12.62_{\mathrm{a}} \\
7.44_{\mathrm{c}}\end{array}$ \\
\hline \multicolumn{7}{|c|}{ High Acid Level } \\
\hline $\begin{array}{l}\text { Control } \\
\text { Low fructose } \\
\text { Low glucose } \\
\text { Low sucrose }(\mathrm{Em}) \\
\text { Low sucrose (Ew) } \\
\text { High fructose } \\
\text { High glucose } \\
\text { High sucrose (Em) } \\
\text { High sucrose (Ew) }\end{array}$ & $\begin{array}{l}12.38_{\mathrm{a}} \\
11.97_{\mathrm{a}} \\
11.82_{\mathrm{ab}} \\
11.32_{\mathrm{ab}} \\
11.62_{\mathrm{ab}} \\
9.91_{\mathrm{c}} \\
11.97_{\mathrm{a}} \\
9.32_{\mathrm{c}} \\
10.53_{\mathrm{bc}}\end{array}$ & $\begin{array}{l}0.68_{\mathrm{f}} \\
2.15_{\mathrm{de}} \\
1.09_{\mathrm{f}} \\
3.50_{\mathrm{c}} \\
1.44_{\mathrm{ef}} \\
7.24_{\mathrm{b}} \\
3.18_{\mathrm{cd}} \\
9.85_{\mathrm{a}} \\
6.88_{\mathrm{b}}\end{array}$ & $\begin{array}{l}11.18_{\mathrm{ab}} \\
10.53_{\mathrm{abcd}} \\
11.65_{\mathrm{a}} \\
10.09_{\mathrm{bcd}} \\
10.97_{\mathrm{abc}} \\
9.76_{\mathrm{cd}} \\
10.82_{\mathrm{abc}} \\
7.62_{\mathrm{e}} \\
9.38_{\mathrm{d}}\end{array}$ & $\begin{array}{r}0.91_{\mathrm{d}} \\
1.56_{\mathrm{d}} \\
1.18_{\mathrm{d}} \\
3.03_{\mathrm{c}} \\
1.65_{\mathrm{d}} \\
6.35_{\mathrm{b}} \\
2.68_{\mathrm{c}} \\
10.26_{\mathrm{a}} \\
6.38_{\mathrm{b}}\end{array}$ & $\begin{array}{c}11.32_{\mathrm{ab}} \\
11.62_{\mathrm{a}} \\
11.79_{\mathrm{a}} \\
9.91_{\mathrm{bc}} \\
10.74_{\mathrm{ab}} \\
8.56_{\mathrm{cd}} \\
10.50_{\mathrm{ab}} \\
7.44_{\mathrm{d}} \\
8.82_{\mathrm{cd}}\end{array}$ & $\begin{array}{l}0.82_{\mathrm{e}} \\
1.79_{\mathrm{de}} \\
1.56_{\mathrm{e}} \\
3.74_{\mathrm{c}} \\
2.03_{\mathrm{de}} \\
9.18_{\mathrm{b}} \\
3.06_{\mathrm{cd}} \\
11.12_{\mathrm{a}} \\
7.97_{\mathrm{b}}\end{array}$ \\
\hline
\end{tabular}

Note-Means with different alphabetic subscripts within a column and acid level are significantly different at $p \leq .05$; means are across 17 panelists and 2 replications. Scale values correspond to $0=$ none, $3=$ mild, $7=$ mild to moderate, $11=$ moderate, and $15=$ moderate to high . Em, equimolar; Ew, equiweight.

with fructose and glucose. Also, an interesting anomaly, albeit nonsignificant $(p>.05)$, was noted in low sugar level mixtures of glucose with lactic and malic acids at both acid levels and of fructose with malic acid at both acid levels, where the sugar-acid mixture was perceived to have a higher sourness than the corresponding acid control.

The $\mathrm{pH}$ of all the mixture solutions was dictated by the $\mathrm{pH}$ of the acid type and level present in the mixture, and so the $\mathrm{pH}$ of the low citric acid control and the corresponding mixtures was $2.63 \pm 0.01$, whereas that of the highacid control and the mixtures was $2.45 \pm 0.01$. The $\mathrm{pH}$ of the lactic acid controls and mixtures at the low and high acid levels was $3.45 \pm 0.01$ and $3.39 \pm 0.01$, respectively, whereas that of the malic acid controls and mixtures was $2.82 \pm 0.01$ and $2.54 \pm 0.01$ at low and high acid levels, respectively.

Trends within sugars and across acids. Figures $3 \mathrm{~A}-3 \mathrm{~F}$ show degree of sourness suppression as a function of perceived sweetness of sugars at equiweight levels. From a comparison of glucose-acid mixtures shown in Figures 3A and $3 \mathrm{~B}$ versus Figures $3 \mathrm{C}$ and $3 \mathrm{D}$ (fructose-acid mixtures) and Figures $3 \mathrm{E}$ and $3 \mathrm{~F}$ (sucrose-acid mixtures), it appears that the glucose-acid mixtures behaved differently than did the acid mixtures with the other sugars. The glucose was perceived to impart some sweet taste, but it did not show much corresponding sourness suppression (degree of suppression not exceeding 1 at the levels examined). The acid-sugar mixtures of fructose and sucrose showed marginally higher suppression in the mild sweetness intensity range and substantially higher suppression in the mild-to-moderate sweetness intensity range.

\section{The Effect of Equisweet Sugar Concentrations}

Within the three perceptually sweetness-matched levels, the sweetness ratings for the sugar types were not significantly different, demonstrating the success of the sweetness matching (Figure 4). The corresponding sourness ratings for the mixtures were similarly not significantly different from each other but were significantly different from the acid-only and sugar-only controls at all three equisweet levels (Figure 4).

\section{DISCUSSION}

Across acid types and levels, it was found that equiweight and equimolar levels of the sugars effected unequal amounts of sourness suppression in terms of a decrease in perceived sourness intensity ratings. If the suppression at either the equiweight or the equimolar sugar level had been equivalent across the acids, physical sugar parameters or molecular mechanisms would be the likely cause of such suppression. However, the results imply that neither completely explains the observed suppression. Although a sugar concentration effect is undeniable (because it is linked to sugar weight, sugar molarity, and perceived sweetness), in the context of our stated objectives, sugar weight or sugar molarity alone did not account for the suppression seen.

To better examine the effect of the perceived intensity of the masking agent on the target taste, the three sugars were selected for the property of being ranked in their perceived sweetness intensitiy at equal weight levels. Shallenberger (1993) averaged the findings of several taste studies to show that on a weight basis, when sucrose has a 
(A) Suppression by Glucose (Ew) at Low Acid Levels

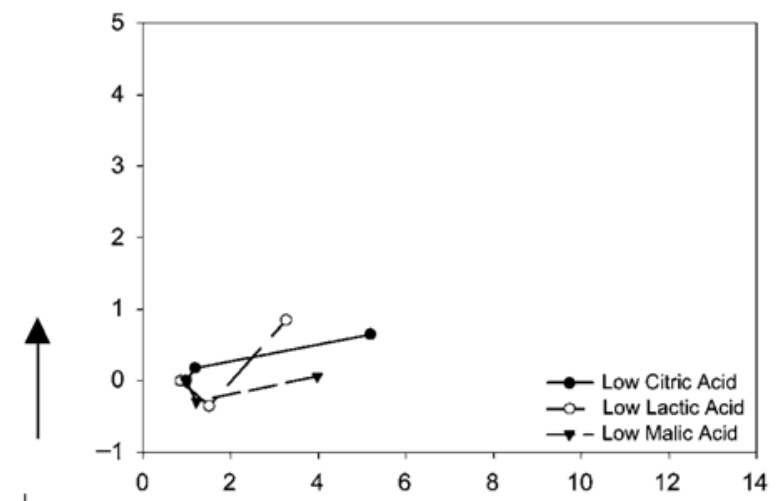

(C) Suppression by Fructose (Ew) at Low Acid Levels

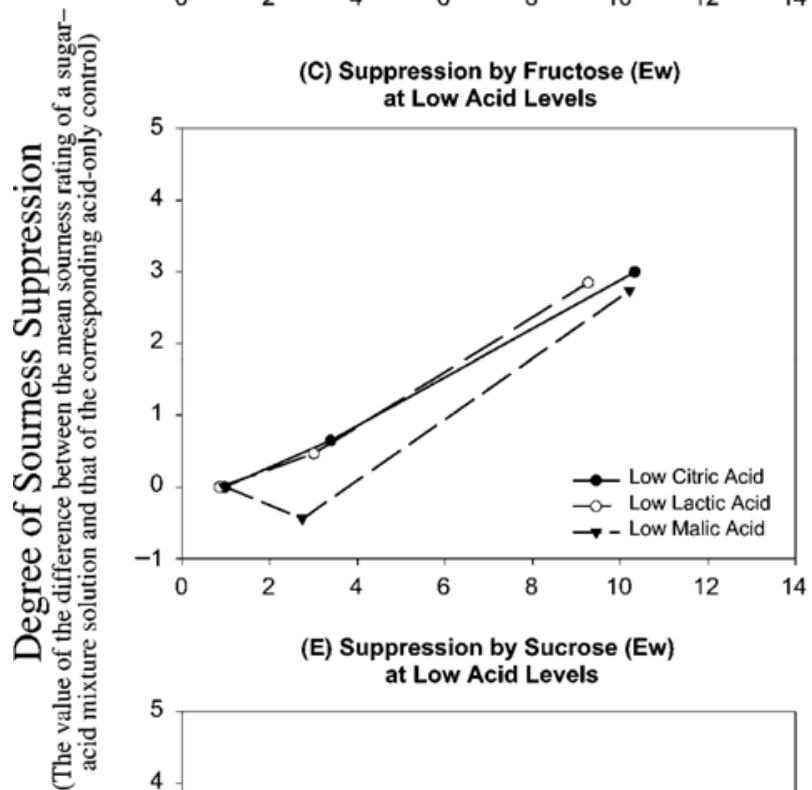

(E) Suppression by Sucrose (Ew) at Low Acid Levels

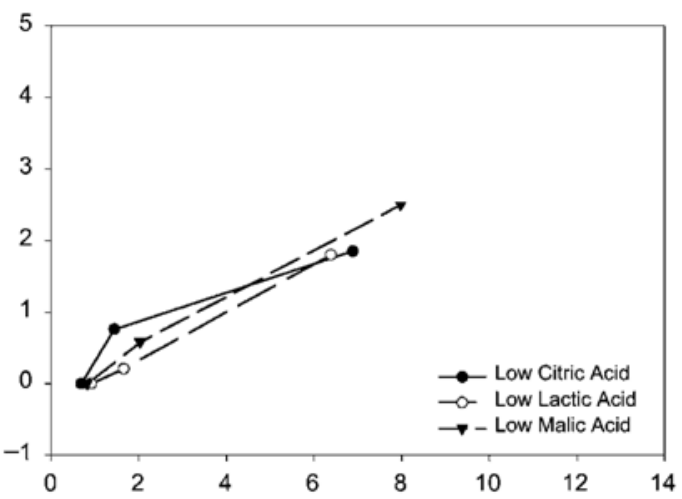

(B) Suppression by Glucose (Ew) at High Acid Levels

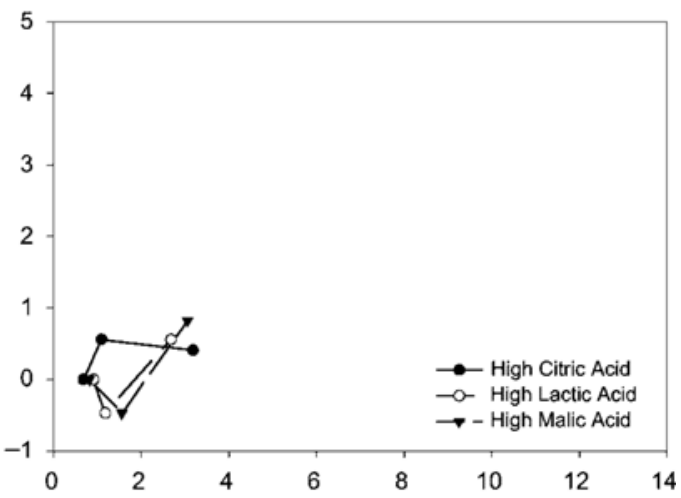

(D) Suppression by Fructose (Ew) at High Acid Levels

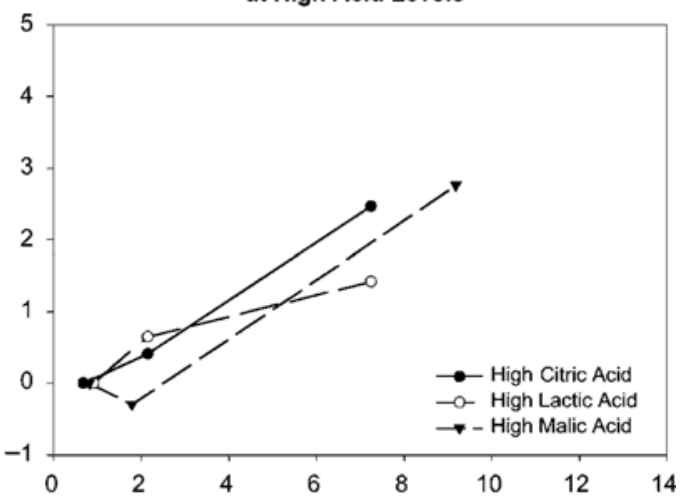

(F) Suppression by Sucrose (Ew) at High Acid Levels

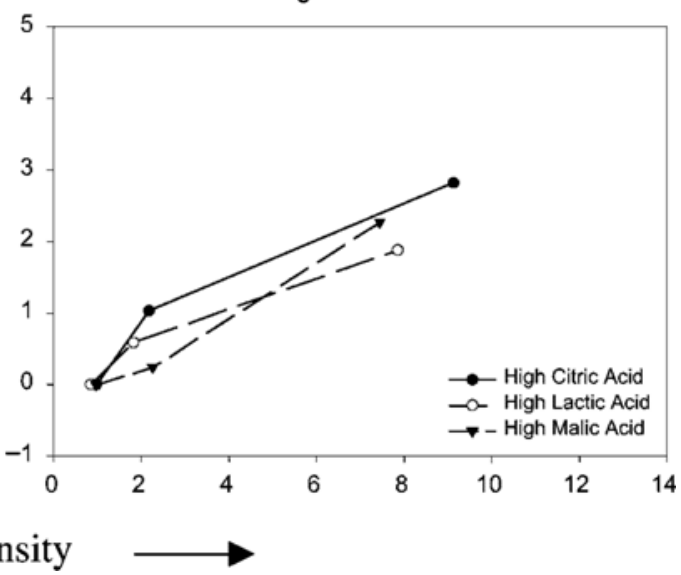

Figure 3. Degree of sourness suppression as a function of sweetness by equiweight (Ew) sugars across acid types.

relative sweetness of 100 , the average relative sweetness of D-glucose is 64, whereas that of D-fructose is 120.5 , making fructose the sweetest of the three. On the other hand, on a molar basis, sucrose is the sweetest of the three.

As can be seen from the mean values in Table 2, at equimolar sugar levels, sucrose mixtures were found to be the sweetest, and the glucose mixtures were the least sweet.
Thus, the order of perceived sweetness intensities of the individual sugars, as predicted by Shallenberger (1993), was also observed in mixtures of the same sugars with the three acids at two levels each; this order of perceived sweetness was translated into a corresponding suppression of sourness, with sucrose suppressing more than fructose, which in turn suppressed more than glucose. 


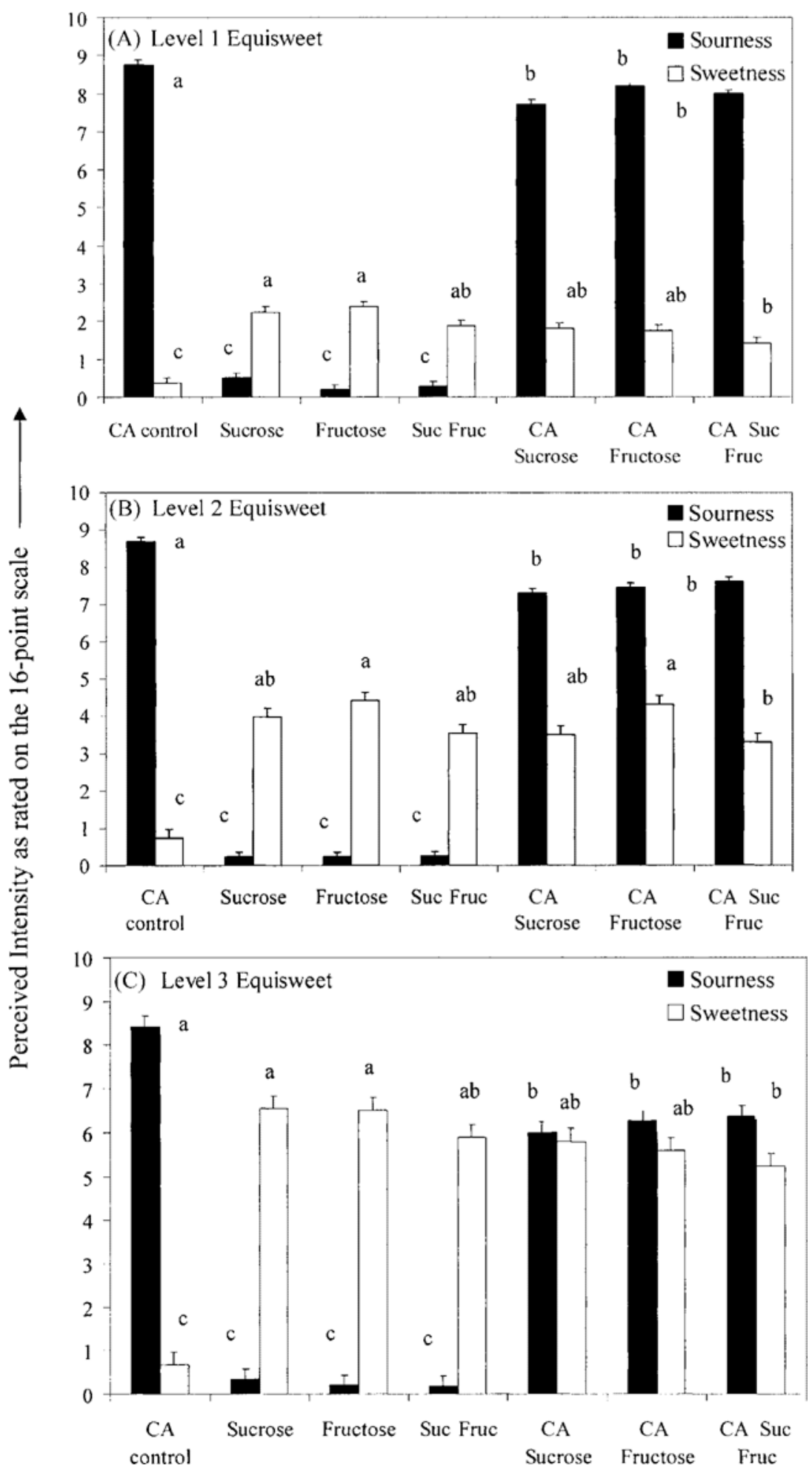

Figure 4. Sourness and sweetness ratings at Equisweet Levels 1, 2, and 3. CA, citric acid.

With sugars on an equiweight basis, fructose mixtures were the sweetest and the glucose mixtures were the least sweet at the low acid level, as was expected. But at the high acid level, there were no significant differences $(p>.05)$ between the sweetness ratings of the fructose and the sucrose mixtures. These results are in accordance with Cardello, Hunt, and Mann (1979), who similarly observed that fructose, which has a sweetening advantage over su- 
(a) Impact of Sugar Sweetness on Degree of Sourness Suppression

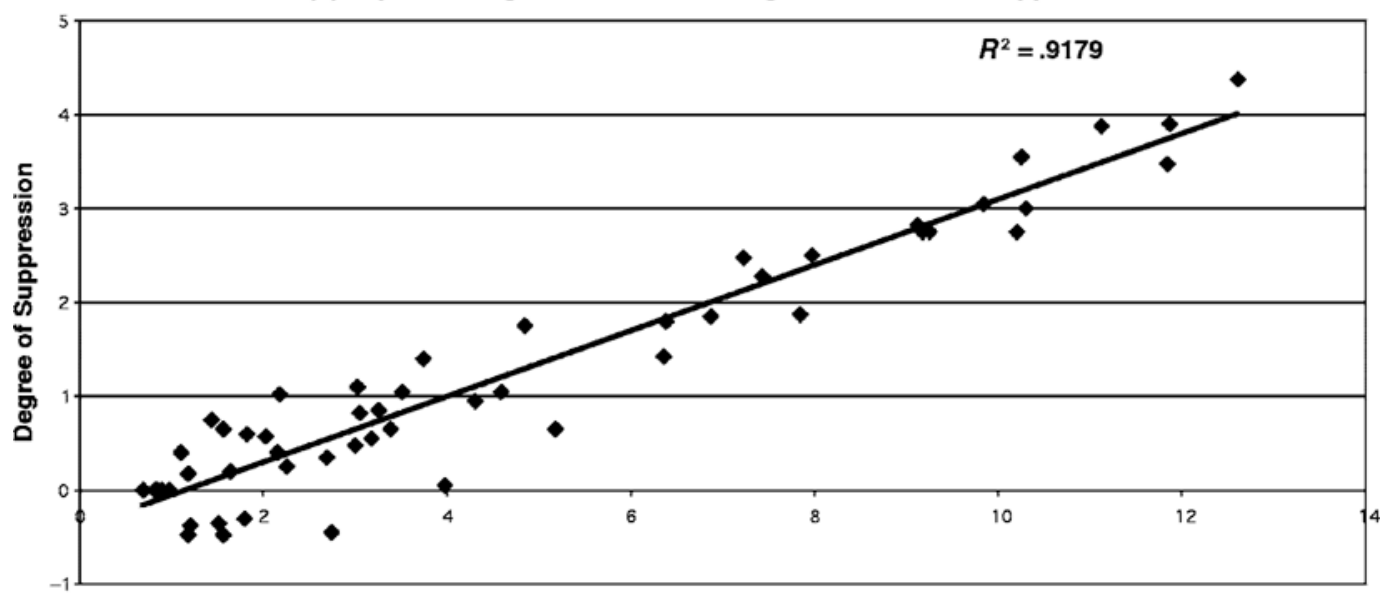

Sugar Sweetness in mean scale values (on a 16-point intensity scale)

(b) Impact of Sugar Molarity on Suppression of Sourness

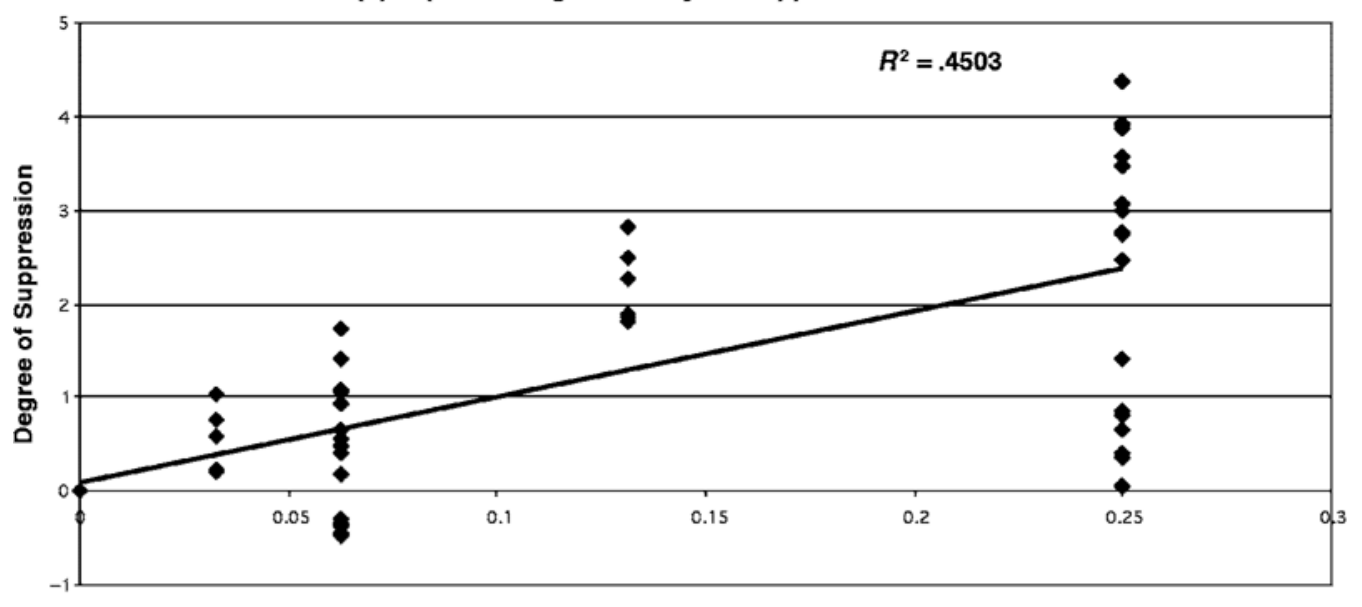

Sugar Molarity in mols

Figure 5. Degree of sourness suppression versus sugar sweetness, sugar molarity, and sugar weight across all the acid and sugar mixture data.

crose in model distilled water solutions, as well as in low acid media at low sugar concentrations, loses this advantage in highly acidic solutions. Thus, at the high acid level, fructose and sucrose mixtures with all three acids were found to be similar in their sweetness ratings and similar in terms of the corresponding sourness ratings $(p>.05)$. Consequently, although it seemed likely that the perceived sweetness intensities of sucrose and fructose determined the extent of sourness suppression, this needed to be confirmed by directly examining the effect of equisweet sugar concentrations on suppression.

The results from the confirmatory study showed perceived sweetness intensities of sucrose and fructose to be the main determinant of sourness suppression of citric acid. At all three sweetness-matched levels examined, the resulting suppression in the acid-sugar mixtures was not significantly different irrespective of sugar type (i.e., su- crose, fructose, or an equisweet mixture of the two; Figure 3). Given that only perceived sweetness, and not sugar concentration, is equivalent at equisweet levels and that equisweet sugar levels produced equivalent suppression in sugar-citric-acid mixtures, it appears that sourness suppression is mostly perceptual and a result of higher order processing at the brain level, as opposed to the peripheral level. These findings demonstrate that central processing mechanisms may be largely responsible for the observed behavior, where central refers to levels higher than the nucleus of the solitary tract (Norgren \& Leonard, 1973).

With respect to glucose mixtures across acid types and levels, glucose contributed sweetness mostly at the high sugar level. But the corresponding sourness ratings did not reflect this, since they remained largely unchanged from the sourness rating of the no-sugar control. A comparison of the suppressive ability of the three sweeteners as a func- 
tion of their perceived sweetness across acid types and levels shows that glucose (Figures 3A and 3B) appears to behave differently than fructose (Figures $3 \mathrm{C}$ and $3 \mathrm{D}$ ) and sucrose (Figures $3 \mathrm{E}$ and $3 \mathrm{~F}$ ) in the range of concentrations examined. With two out of three acids, glucose mixtures (Figures 3A and 3B) showed a trend of initial sourness enhancement, followed by marginal sourness suppression in mixtures. Fructose mixtures (Figures $3 \mathrm{C}$ and $3 \mathrm{D}$ ) showed initial sourness enhancement only with malic acid and suppression with citric and lactic acids. Sucrose mixtures showed sourness suppression with all three acids. On the basis of the observed response patterns, in general, glucose appears to be a less effective suppressor of sourness, as compared with sucrose or fructose, in a low range of perceived sweetness. To confirm this, more data would be needed in the region of higher perceived sweetness values for glucose. However, a distinct response pattern to the same acids and differential efficacy as a suppressor, as compared with sucrose and fructose in a similar range of perceived sweetness, points toward separate receptors/ receptor mechanisms for the different sugars and, thereby, a peripheral component to suppression.

Work with quinine-sucrose mixtures (Lawless, 1979, 1982) has also shown the possible existence of a peripheral component to mixture suppression, in addition to the central. Thus, in contrast to Schifferstein and Frijters (1991), who deemed mixture suppression to be a purely perceptual phenomenon and who found it unlikely that it could be accounted for by receptor events, we believe suppression to have both receptor-related and perceptual components. This supports Kroeze's (1989) idea that the phenomenon of mixture suppression should be viewed as a continuum with central and peripheral components, as opposed to one or the other.

In terms of conceptual process models from the realm of integration psychophysics, it has been hypothesized that since homogenous mixtures of fructose-sucrose and fructose-glucose have a sweetness that, at higher concentrations, exceeds that of the individual components, these mixtures follow a separate-sites model. The separate-sites model implies that the two components of the mixture are transduced independently at separate receptor sites (McBride, 1989). Further evidence to support independent receptor sites/mechanisms for the transduction of glucose and fructose has come from the isolation of fructose nontasting and glucose nontasting variants from natural populations of adult and larval fruitflies (Drosophila melanogaster) and from the identification of potential human glucose nontasters by elevated glucose thresholds (Kennedy, Eylam, Poskanzer, \& Saikku, 1997). Another psychophysical study has suggested different receptor cell mechanisms for furanose and pyranose monosaccharides on the basis of human and fruit fly (Drosophila adiastola) response functions. Our results also suggest a mechanism for the pyranose-furanose disaccharide sucrose similar to that of furanose monosaccharides (Armstrong et al., 1998). Our findings on sourness suppression appear to corroborate the findings from the aforementioned studies and support the proposed existence of a separate receptor/ mechanism for glucose from the receptor(s)/mechanism for fructose and sucrose.

It remains to be seen whether the findings from this work using model solutions will be supported in more complex systems. In some cases, as in a study of the perception of sweet-acid mixtures in gels (Barylko-Pikielna, Matuszewska, \& Radzanowska, 1999), this has been supported. It was found that the general rules of behavior observed for the mixtures in water solutions were also followed in gels, with an additional effect of the nature of the gelling agent. More work of this type could eventually lead us away from the current approach, based on trial and error, to determining the ranges for mixture components in real products.

In conclusion, sourness suppression is not mediated by the molarity or weight of the sugar in the binary mixture solutions of the sugars and acids examined. For the sugars sucrose and fructose, the perceived intensity of the masker and, thereby, central neural mechanisms appear to be largely responsible for the observed suppression. The regression equations from overall scatterplots of the degree of sourness suppression versus the perceived sugar sweetness, sugar molarity, and sugar weight confirm the relationship between sourness suppression and perceived sweetness (Figure 5). The data also support the existence of a receptor/mechanism for glucose separate from that for fructose and sucrose and, thereby, a peripheral component to suppression.

\section{REFERENCES}

Armstrong, M. A., Feroz, N., Henderson, M. L., Katsman, Y., Parmar, H. S., Scarsella, L. M., \& Kennedy, L. M. (1998). Human taste mechanisms for pyranose and furanose sugars [Abstract]. Chemical Senses, 23, 557-558.

Barylko-Pikielna, N., Matuszewska, I., \& RadzanowsKa, J. (1999). Taste perception of sweet/acid mixtures in gels. Polish Journal of Food \& Nutrition Science, 8, 49-59.

Bonnans, S., \& Noble, A. C. (1993). Effect of sweetener type and of sweetener and acid levels on temporal perception of sweetness, sourness and fruitiness. Chemical Senses, 18, 273-283.

Cardello, A. V., Hunt, D., \& Mann, B. (1979). Relative sweetness of fructose and sucrose in model solutions, lemon beverages and white cake. Journal of Food Science, 44, 748-751.

Frijters, J. E. R., \& OUdE OpHUIS, P. A. M. (1983). The construction and prediction of psychophysical power functions for the sweetness of equi-ratio sugar mixtures. Perception, 12, 753-767.

Kennedy, L. M., Eylam, S, Poskanzer, J. E., \& SaIKKu, A. R. (1997). Genetic analyses of sweet taste transduction. Food Chemistry, $\mathbf{6 0}_{2}$ 311-321.

KroEZE, J. H. A. (1989). Is taste mixture suppression a peripheral or central event? In D. G. Laing, W. S. Cain, R. L. McBride, \& B. W. Ache (Eds.), Perception of complex smells and tastes (pp. 225-243). Sydney, Australia: Academic Press.

LAWLESS, H. T. (1979). Evidence for neural inhibition in bittersweet taste mixtures. Journal of Comparative Physiology \& Psychology, 93, 538547.

LAWLess, H. T. (1982). Paradoxical adaptation to taste mixtures. Physiology \& Behavior, 25, 149-152.

McBride, R. L. (1989). Three models for taste mixtures. In D. G. Laing, W. S. Cain, R. L. McBride, \& B. W. Ache (Eds.), Perception of complex smells and tastes (pp. 265-282). Sydney, Australia: Academic Press. 
McBride, R. L., \& Finlay, D. C. (1990). Perceptual integration of tertiary taste mixtures. Perception \& Psychophysics, 48, 326-330.

McBride, R. L., \& Johnson, R. L. (1987). Perception of sugar-acid mixtures in lemon juice drink. International Journal of Food Science \& Technology, 22, 399-408.

McCarthy, M. J., Heil, J. R., Krugermann, C., \& Desvignes, D. (1991). Acid requirement for $\mathrm{pH}$ modification of processed foods. Journal of Food Science, 56, 973-976.

MeilgaARD, M., Civille, G. V., \& CARR, B. T. (1991). Measuring responses. In Sensory evaluation techniques (2nd ed., pp. 53-54). Boca Raton, FL: CRC Press.

Moskowitz, H. R., \& Sidel, J. L. (1971). Magnitude and hedonic scales of food and acceptability. Journal of Food Science, 36, 677-679.

Norgren, R., \& LeONARD, C. M. (1973). Ascending central gustatory pathways. Journal of Comparative Neurology, 150, 217-238.

PANGBORN, R. M. (1961). Taste interrelationships: II. Suprathreshold solutions of sucrose and citric acid. Journal of Food Science, 26, 648-655.

RISKEY, D. R. (1988). Uses and abuses of category scales in sensory measurement. In H. Moskowitz (Ed.), Applied sensory analysis of foods (Vol. I, pp. 177-192). Boca Raton, FL: CRC Press.

Rubico, S. M. (1993). The use of power functions and a directional dif- ference from control test to determine equi-sourness levels of selected acidulants. In Perceptual characteristics of selected acidulants by different sensory and multivariate methods (pp. 77-109). Unpublished doctoral dissertation, Oregon State University.

Schifferstein, H. N. J., \& Frijters, J. E. R. (1991). The effectiveness of different sweeteners in suppressing citric acid sourness. Perception \& Psychophysics, 49, 1-9.

SHALlENBERGER, R. S. (1993). Sweetness and other taste attributes of the sugars. In Taste chemistry (pp. 189-197). London: Blackie Academic \& Professional.

Sognefest, P., Hays, G. L., Wheaton, E., \& Benjamin, H. A. (1948). Effect of $\mathrm{pH}$ on thermal process requirements of canned foods. Food Research, 13, 400-416.

SPSS Version 8.0 [Computer software] (1997). Chicago: SPSS, Inc.

STEvens, S. S. (1956). The direct estimation of sensory magnitude: Loudness. American Journal of Psychology, 69, 1-25.

Stevens, S. S. (1957). On the psychophysical law. Psychological Review, 64, 153-181.

(Manuscript received October 22, 2002; accepted for publication March 13, 2003.) 